\title{
Role of Coordination in Effective Public Service Delivery System
}

\author{
Ajay Gautam \\ Centre for the Study of Law and Governance \\ Jawaharlal Nehru University \\ New Delhi 110067, India \\ E-mail:-ajay.k.gautama@gmail.com
}

Received: June 19, 2020 Accepted: July 20, 2020 Online published: September 2, 2020

doi:10.5296/jpag.v10i3.17205 URL: https://doi.org/10.5296/jpag.v10i3.17205

\begin{abstract}
Governance and delivery of public services are aimed at managing limited available resources to effectively deliver services to the citizens of a country. However, due to lack of coordination management, personal political gains and inclusion of politics, citizens are deprived of the required information and infrastructure. This deprivation not only results in economic losses but also causes deterioration of the state of social well-being. Indian public administration has suffered from the problem of coordination due to which in many aspects the objective of benefitting the citizens is not fulfilled. This study is focused on examining the role of coordination in the public service delivery system. By comparing the Indian public delivery service system with those of Uruguay and Georgia, this study reveals that presence of coordination among the organizations, agencies, and departments improves transparency, accessibility of information, institutional capacity, and innovativeness of a country. Hence, for effective delivery of public services to citizens, maintenance of coordination is essential.
\end{abstract}

Keywords: coordination, public service delivery, Public Service Guarantee Act, At You service programme, Public Administrative Reforms

\section{Introduction}

Coordination is simply considered as 'an act of coordinating or making different things or people work together in order to fulfil a common goal' (Král, 2007). It is the integration of diverse environments, boosting the efficiency of operations to enhance the chances of success. It is the act of unification, synchronization, and integration among stakeholders towards a common goal(Juneja, 2015). Malone, (1988) defined the coordination theory as 'the management of the dependencies among present independent activities.' By focusing on the 
aspect that the matter of concern is not the activities themselves but the interplay among the activities, Malone gave the concept of coordination an economic and business perspective. Král, (2007) \& Vanagas and Stankevič, (2015) further added that as interdependencies do exist, there is a need to coordinate. The coordination could be internal as well as external. External coordination consists of the coordination of the institution or organization with external entities such as the government, competitors, customers, or suppliers; whereas the internal coordination defines the balance between the people working in the organizations and the activities performed. The effective working of a project requires the maintenance of both.

The presence of internal and external coordination enables working in a dynamic environment, maintaining a constant flow of information, helps in specialisation, promotes group efforts and high performance, and create synergies. The relevance of all these aspects can be seen in each working platform but often the model of coordination theory is studied in the organisation context (Boella \& Torre, 2006).

Like the complex functioning of organisations, the public sector must also manage different bureaucratic systems to ensure the effective delivery of public services. With the availability of limited public resources, there is a need to meet the growing expectations of citizens and ensure the delivery of services in a way that human rights are respected, and transparency in the working framework is maintained (Thornton, 2019). However, due to bureaucrats' inability to coordinate their activities efficiently, lack of collective actions can be witnessed in several public service systems. Peters, (2018) stated that governments are more resistant to coordination in the working due to concerns of confidentiality. In public administration information is power, and therefore lack of coordination is detrimental to its being. Further, supporting the viewpoint of Osborne, Hughes and Kickert (2010) and Stinchcombe (2015), Peters mentioned that political parties vary in their beliefs and ideologies. These differences lead to implementation of their own policies and budget, and hence to prevent endangerment of their turf, coordination existence is often ignored.

In India, the government is working towards poverty eradication through several social welfare programs, policies, and schemes; however, they have thus far tasted limited success in the achievement of their goals. The policies and schemes were formulated to strengthen the public service delivery system but with respect to their execution, the Indian public service administration has a long way to go due to its usage of traditional methods for connecting citizens (Paramashivaiah \& Suresh, 2016). Further, the presence of middlemen in the delivery mechanism requires extra cost for the timely delivery of the services. The nonexistence of an organic relationship degrades the functioning of the administration and give rise to the problems like corruption, lack of accountability, red- tapism, maintenance of capacity gaps, and a crooked system. All these issues limit the outcome of the public services and reserve the benefit for certain hands (Vembu, 2019;Afridi, 2017).

Thus, focusing on the challenges faced by the government in instilling coordination in their working mechanism, this study aims at analysing the aspect of coordination concerning the public sector organizations. 


\section{Literature Review}

\section{a) Importance of Coordination in the Public Delivery Systems}

The economic growth of a country is dependent on the growth of human capital, poverty, and equality. Governance and the delivery of public service are maintained in a country to control these aspects of growth and maintain a balance between the development level of people (Shah, 2005). However, with the inclusion of politics and for personal political gains, these essentials are overlooked. These differences in development levels are mainly dependent on the pattern of public service delivery in a country (Thornton, 2019). Every government has independent organizations that control the delivery of similar or different public services. As long as the functioning of the government is at a small level and under the control of a central authority or monarch, the work is done in a coordinated way (Humphreys, 1998; Lægreid, Verhoest, \& Jann, 2008; Thomas \& Rubinstein, 2017). However, as the range of activities increases and the coverage of the government reaches larger geographical areas, the coordination works as a 'philosopher's stone' i.e. more failures tend to occur in programmes (Bouckaert, Peters, \& Verhoest, 2010).

As the responsibility and complexity in the working pattern have increased with the recent trends like promotion of digital environment, there is a greater need for transparency in the working process (Peters, 2018). The growth of bureaucracies to meet these demands has led to the maintenance of coordination more challenging among the MDAs (Ministries, Department, and Agencies). This poor coordination not only decreases the efficiency and productivity of the government but also enables it to take inaccurate decisions in the absence of complete information (Afridi, 2017; Worldbank, 2018). Further, efforts can prove futile and duplication of work occurs due to lack of coordination. Even in the case of the public service delivery system, since poor coordination leads to ineffective maintenance of information collected from the citizens, customers must sometimes invest extra money and time to fulfil similar requirements repeatedly (Worldbank, 2018). Hence, good coordination helps in giving direction to the working of MDAs and reduce citizens' burden, making it a critical aspect of the system.

\section{b) Problems in Coordination}

A report by Worldbank, (2018) stated that with a growth in the size and volume of responsibilities of a government in a nation, the management of the has become increasingly complex. Expansion of government ministries, agencies, and departments mandated the need to fulfil the growing expectation of the citizens for more and better services. However, this caused a rift among the departments serving citizens. Existence of separate MDAs needs the collective actions of the government to enable smooth operations but the separation of MDAs brought in the challenge of maintaining coordination.

A survey by OECD (2016) revealed that despite most countries focusing on the achievement of sustainable development goals, the lack of inter-agency coordination hampers the implementation of the programmes. In many cases, structured containment of various social problems is difficult because of the poor ability of MDAs to work together. Further, OECD (2018) report mentioned that to align the activities of the government towards the accomplishment of the objectives and clearly stating the role and responsibilities of each 
department, the maintenance of inter-institutional coordination is instrumental. However, due to lack of capacities at the sub-national level, lack of institutional mechanisms to maintain the coordination among the departments, and lack of common interest of all sub-national stakeholders, the problem of coordination persists in public governance.

\section{c) Methods of Coordination}

Bouckaert et al., (2010) considered the relevance of coordination in the maintenance of the working structure of public sector organization stated that there are three main approaches which can be used by the government to implement coordination in operations. Firstly, the hierarchical mechanism of coordination wherein the priority of organization is to get work done through the legislative authority instead of power i.e. 'control strategy is used to base their actions in favour of their decisions which otherwise could not be done voluntarily' (Alexander APD, 1998). This method of governance helps in controlled working and thus maintenance of coordination. The second form of coordination mechanism is market-based i.e. transparency is maintained in the working process by providing incentives to provide complete information about each department to others. Herein Alexander APD, (1998) stated that 'no common formal linkage is required and the coordination exists due to mutual adjustments of the departments as per the perceived environment'. Lastly, the network mechanism of coordination could be used i.e. voluntary coordination is maintained between the organizations by building in the connections between the different departments. Herein, through cooperation and solidarity, the government builds a trust-based network between the different MDAs to promote voluntary collaborative actions. Klijin \& Koppenjan, (2000) stated that in network-based coordination 'stable pattern of cooperative connection between the mutually dependent actors is created around the specific issues of management or policies.'

Further, Worldbank (2018) discussed some other global methods of maintaining coordination. The report stated that existence of political leadership where the president or the prime minister focuses on the existence of coordination, enhancement of institutional capacity to maintain coordination, provision of incentives like rewards or sanctions for coordinated working, increase in transparency for the internal and external stakeholders, and development of technology for coordinated last-mile service delivery would help in maintaining a collaborative working environment in public service delivery system (Thomas \& Rubinstein, 2017).

\section{Methodology}

To examine the relevance of coordination in the public delivery system, the researcher uses the pragmatic research philosophy. Herein focusing on the perspective of the researcher, the coordination problem in the Indian administrative services would be analysed. This analysis provides an incentive to explore the non-existence of coordination that curbs the mechanism of public service delivery. Due to which in many cases citizens are unable to access public services and facilities.

Secondary data present in the form of books, research papers, government websites, news articles. And official reports of government agencies have been used in this research.

A descriptive research design is used through which, the entire working process of the public 
service delivery system is analysed. Further, the importance of coordination in the public service delivery system was examined by reviewing the work of other researchers. Herein, case-study method is used to examine the real scenarios related to the public service delivery system and derive information about the role of coordination in managing its working. Three case-studies for the analysis have been selected based on the globally transpired incidents/scenarios/changes within the last 10 years. Further, a comparison of the cases is presented to determine the essential components of better delivery of services to the citizens.

Databases such as ICPSR, CORE, ScienceOpen, SSRN, and Semantic Scholar were referred to. Inclusion and exclusion criteria for the studies were decided by the researcher before using them for this research. The inclusion criteria included: studies that were no older than 2000, studies that were obtained from credible sources, and for which full access was available in the English language.

\section{Discussion}

This section of the study is focused on examining the problems of coordination in the Indian public service delivery system along with having the assessment of the three different cases of administrative public service delivery wherein coordination has affected the mechanism of service delivery. Understanding the relevance of coordination in managing the public services, this section would help in comparing the coordination level in Indian with the other countries' cases and identifying the changes that are required for enabling effective public service delivery in India.

\section{a) Problems of Coordination in Indian public service delivery system}

To alleviate poverty in India, public policies are mainly focused on offering free or subsidized delivery of the essential or basic services to the citizens but broadly, India failed to effectively deliver services to citizens, especially the poor (Dreze \& Sen, 2013). In the absence of a social security program to provide food security, Public Distribution System (PDS) is used. However, it suffers from several challenges such as pilferage and theft of the grain in the open market (Drèze \& Khera, 2015). The second-largest social program of the country, the MNREGA program which aims to provide 100 days assured employment (MGNREGA) to the poor, faces issues such as poor targeting and misappropriation i.e. unorganized working, non-purposive spending, Maoist insurgency (less than $9 \%$ of households in Maoist militancy affected areas got this facility), and lack of manpower (Chaarlas \& Velmurugan, 2012). Even in the case of public provision of education, although there has been an increase in investment in building schools, training teachers, and improving existing infrastructure, the quality of education is poor which is reflected in high dropout rates i.e. $17.06 \%$ in 2016 (Statista, 2020). Along with this, there is corruption, no proper value, poor rates of women's education, lack of facilities (only $68.7 \%$ of schools in 2016 survey has useable toilet facility), and absenteeism (Nadar, 2018). These low levels of access to basic facilities indicate the ineffectiveness and inefficiency of the Indian administration in delivering public services. Afridi, (2017) stated that the major factors that lead to this inefficiency are the existence of corruption, lack of transparency, absence of a monitoring mechanism, capacity gaps (less manpower), and lack of accountability (World Bank, 2006). These problems can be addressed 
by the creation of new agencies, specialization, or increasing capacities but these solutions would further lead to the problem of dysfunctional autonomy, transaction cost, and disconnection of various departments working under a single policy. Thus, to overcome these problems, it is essential to re-establish new coordination mechanisms among hierarchies, markets, and networks (Bouckaert et al., 2010). Coordination would help in encouraging communication among the internal and external departments of the public sector, leading to an easy flow of information among the departments and facilitating better management of complex operations by real-time monitoring (OECD, 2008). Despite the relevance of coordination in managing the working of public administration, maintenance of coordination was never a matter of concern in India. Since government projects are huge, needing the involvement of many organizations and stakeholders in the process before and after implementation, there is a need for collaboration among stakeholders, and communication synchronization for reducing the difficulties in the process. However, due to the non-availability of coordination in the Indian public service delivery system, the administration witnessed failure in fulfilling the objectives of critical programs such as the telemedicine project of West Bengal (Sundar, Garg, \& Garg, 2015). Thus, though recently there has been cognisance of the relevance of coordination in the public delivery system, and that there are several departments that are lagging behind and require greater capacity, accountability, transparency, and monitoring through coordination for having effective public service delivery.

\section{b) Case-based analysis of the coordination}

Herein, the focus is on assessing the coordination in the public administration system of India. For this purpose, a comparative overview of three critical public sector projects is drawn- the Public Service Guarantee Act of India, the At Your Service program in Uruguay, and Public Administrative Reforms Roadmap 2020 of Georgia. The comparison of these three cases helps understand the difference in the coordination mechanisms of the countries and helps identify the aspects which are required to be modified in the Indian administrative system for better functioning. Uruguay ranked 57 in the Human Development Index; Georgia at 70 and India at 129; thus, a comparison of the performance would help in identifying the factors which would improve the distribution of services to the citizens. Moreover, although Uruguay and Georgia are smaller in size than India, the total expenditure by the governments of these countries is more than that incurred by the latter- with $33.21 \%$ in Uruguay, $29.72 \%$ in Georgia, and $26.18 \%$ in India. Further, the Indian government began its efforts for better coordination was much before the other two countries (2010 in India while 2013 in Uruguay and 2014 in Georgia). However, the performance by Uruguay and Georgia was better than India's. Thus, this analysis would help in identifying the areas where India is lagging. The section below analyses each case individually.

\section{i. Case 1: The Public Service Guarantee Act, 2010 in Madhya Pradesh, India}

Madhya Pradesh (MP) is a state in Central India with a majority of its population belonging to the lower middle-income and disadvantaged groups. Before 2010, only a small proportion of its population trusted the services provided by the government agencies. People tried to keep minimum interaction with the officials. In 2010, the Public Service Guarantee Act was passed by the MP government to legislate the rights of its citizens by promising them the 
delivery of some specified services within a certain timeframe. Although the program was implemented, due to its inherent complexity and non-coordinated working environment, the delivery of services was getting delayed. Further, the limited reach of the benefits was a problem, which led to the requirement of several days for travelling and availing benefits of the services. Even the non-coordinated work led to the provision of poor-quality service (Worldbank, 2018). For overcoming all these challenges, the Department of Public Service management was created which was responsible for coordinating the services between the agencies and implementing the newly passed legislation effectively (Murilidharan, 2016; SAPS, 2014). Madhya Pradesh State Agency for Public Services (MPSAPS) was built to facilitate coordination between all stakeholders and ensure timely delivery of services. For strengthening the public service delivery further, the department signed the MPCARS project wherein public management reforms were undertaken to improve the accessibility of public services for citizens, especially marginalized groups. Technical assistance was provided to government programs, effective project management was undertaken and ICT was strengthened. The department also worked on having the informational technology management, monitoring the development of integrated management information systems, and their implementation by coordinating with National Informatics centers (NIC). Thus, this department works towards overcoming the existing biggest challenge of lack of accountability and non-existence of the time-bound delivery system and provides the benefit of assuring services, accountability, penalty/compensation, disposal within timelines, and grievance redressal (Thornton, 2019).

'People service centers' also called the Lok Sewa Kendras (LSK) were opened in each of 300 blocks of MP. This LSK network was further expanded by opening kiosks through which citizens could connect with national and state government. By 2016 around 6500 'Citizen service centres' and 3200 'MP online' kiosks were opened and by 2017, and around 80 more public services were provided through this scheme with a coverage of more than 30,000 locations in MP (WorldBank, 2015). The efficiency of the working mechanism was improved by keeping a digital database for recording all the information about the citizens. This reform not only reduced the wastage of time and money but also raised the transparency in the mechanism (O’Meally, Chowdhury, \& Piplani, 2017). Till 2018, the scenario was such that a total of 428 public services was provided through the Public service Guarantee Act from which about 200 services had availability of a digital platform to manage things. Governments of more than 20 states of India also implemented this Act in their respective states (Thornton, 2019). Regarding this development, Menon said that, 'Madhya Pradesh has shown that what you need is a focused administrative mechanism that supports implementation of the PSGA'(Worldbank, 2018).

This case of Madhya Pradesh shows that Public Service Guarantee Act has covered all the dimensions required for effective delivery of public service by working on the maintenance of coordination in the department. By following the all methods stated by the Worldbank (2018), this Act has a provision of political leadership. As being the first state to implement the act for legislating the rights of citizens, MP government motivated the governments of many other Indian states too for taking a similar step. Further, by opening a new department called Department of Public Service Management, opening LSKs and kiosks, and creating 
more than 300 one-stop shops, under this Act, the MP government raised the institutional capacity of the MDAs. Lastly by providing the digital platform and keeping an online database of citizens' documents, the MP government worked towards implementing new technology and bringing in transparency in the mechanism. Thus, the Public Service Guarantee Act, 2010 of Madhya Pradesh has shown that until horizontal and vertical coordination is not maintained, the effective delivery of public services could not take place and citizens could not trust the working structure of government.

\section{ii. Case 2: At your service - The government-NGO partnership in Uruguay}

Every February in Uruguay- a country with many high-income people- healthcare service providers are engaged in launching different marketing campaigns to make people switch their healthcare plans. These services are provided by the public, semi-private, or private providers. Confused by a variety of options, citizens of Uruguay chose the one that provided the most value for money. Fabrizio Scrollini, regarding the situation of Uruguay citizens, said that 'Citizens were essentially navigating in the dark. You wouldn't know how many doctors a provider had, how much they charged you, or if the provider complied with national targets' (Worldbank, 2018).

To ease this situation and help people, in 2008, Ministry of Public Health published the healthcare information online but due to complexity in the dataset most people could not understand the database. Considering this availability of data as an opportunity, in 2013, DATA Uruguay partnered with portal 180 to provide the Ministry of Public Health (MSP) database online. They developed a tool called 'Transfer Window' which would help visualise the data and further rank the healthcare service providers as per the user preferences. Though the information about the various healthcare plans was available and even 6000 visits were obtained by 2014 but still due to inaccurateinformation, the portal could not work effectively (Scrollini, 2016; Worldbank, 2018).

The government at the time also wanted to build a network for making information available but due to a lack of expertise, this was not possible. Thus, they collaborated with the DATA Uruguay and opened a new Open Government Partnership (OGP) platform with the support of Agencia de Gobierno Electrónico y Sociedad de la Información y del Conocimiento (AGESIC) agency (Sangokoya, Clare, Verhulst, \& Young, 2016; Scrollini, 2016). Although it was decided that collaboration would work, at the time of discussing which information to include, the opinions of both partners were different. DATA Uruguay attempted to make more information available while ministry was cautious about the information needed to be published. There was a difference in objectives for each partner, DATA wanted to allow ease in switching of healthcare service providers by providing information while the Ministry, not primarily focusing on promoting switching, had the objective of improving the system and solving the choice problem (Abierto, 2018). Despite such differences in objectives, but the organisations came to an agreement. There were many other challenges such as data not being present in a standardized format, unavailability of a sophisticated information system to manage the data, and among others. But due to the coordination betweem DATA Uruguay and the government, the website received more than 32,000 visitors in 2015. By 2016 more than $4 \%$ of the population was eligible for changing the healthcare provider using the website (Sangokoya et al., 2016; Worldbank, 2018). 
This case of government-NGO partnership shows that there was a political risk associated with the collaboration of DATA Uruguay and MSP because instead of following a traditional pattern of letting the government dominate the accord, there was a partnership between two different organizations having different perspectives on a particular issue and different goals. With the focus towards providing people better access to information and an opportunity to avail optimal healthcare services, the OGP platform was created. This coordinated effort not only fulfilled the need of government and NGO but also improved the efficiency of health care service delivery to the public through increase transparency in the mechanism of information delivery to citizens of Uruguay about the healthcare plans, created an incentive to compete for healthcare companies by providing better information about their performance to public, and gave the citizens an opportunity to provide suggestions and feedback. Hence, this partnership between the NGO and government of Uruguay depicts that the implementation of coordinated practices make the delivery of public services more effective.

\section{iii. Case 3: Public Administrative Reforms Roadmap 2020 (Georgia)}

With the change of government in 2012, a new program was launched- 'For strong, Democratic, and Unified Georgia'. Recognizing the importance of good public administration for implementation of EU-Georgia Agreements, Government of Georgia (GoG) with the support of Organization for Economic Corporation and Development (OECD) and European Union (EU) launched 'Public Administrative Reform (PAR)'(Gov.GE, 2015). To provide more 'transparent, predictable, responsible, and effective administration'; policies like 'Open Governance Action Plan 2014-2015', 'Public Finance Management Strategy 2014-2017', and 'A Digital E-Georgia Strategy and Action Plan 2014-2018' were initiated. Although these policies were undertaken by the government of Georgia for increasing the efficiency of public administration. the management of each policy is independently done by different ministries (i.e. 'Open Governance Action Plan 2014-2015', and 'A Digital E-Georgia Strategy and Action Plan 2014-2018' by Ministry of Justice and 'Public Finance Management Strategy 2014-2017' by Ministry of Finance) (EU, 2015; Gov.GE, 2015).

Georgia has 19 ministries with more than 200 state-level enterprises and agencies delivering services to the public. The provision of these services is managed by the individual legislative system and there is no universal regulation to ensure the effective delivery of public services (Gov.GE, 2015). Though these services are handled individually, the government cordially work to deliver effective service delivery. The state procurement system was reformed by introducing Unified Electronic System of State Procurement. This electronic conduction of tenders reduced the cost of participation for the public and even made the process more effective, transparent, and unbiased. Further, the one-stop principle was introduced through which all bureaucratic barriers were removed. The process of passport issuance, property, and business registration, or notary services was simplified (Vashakidze, 2016). Even the Public Service halls website was created wherein information about at least 40 types of e-services was available. All these changes in the service delivery system by linking the information available with the government and the public services, not only increased public access to information but also provided them with an opportunity to derive speedy access to the services (PWC, 2015;Becker, 2015).

This case study of changes in public administrative reforms of Georgia showed that effective 
and timely delivery of public services to the citizens depended on the coordination between the agencies. Although, no central administrative authority regulated the functioning of each agency in Georgia, by maintaining a connection between each agency, public services were provided. The process was transparent and the information on state laws that defined the cost of public services was accessible by the people. Further, the implementation of each policy was regulated by a ministry, thus, providing the political leadership to working out a mechanism for public services delivery. Lastly, initiatives such as building of Unified Electronic System, and E-Georgia were undertaken for connecting citizens of Georgia and making all information and services accessible to them. Thus, this study shows that the presence of coordination in the functioning mechanism of the public service system ensures the effective delivery of services to the citizens.

\section{c) Findings}

A comparison of the cases shows that though the Public Service Guarantee Act was successful in that it stated that public service delivery could be elevated by rigid delivery system, multiple delivery channels, and successful public-private partnership, its performance has not met the expectations. Only about $35 \%$ of surveyed applicants received a receipt and officials have never provided a reason for the rejection of the application. Even after having 5 years of implementation of the Act, the awareness level was very low i.e. less than $1 / 3^{\text {rd }}$ of people were aware of the Act. The aim of the Act was also to reduce corruption and minimise the use of middlemen but more than $92.5 \%$ of the surveyed applications were collected by middlemen. Even in the case of MP, Karnataka, Delhi, and Bihar reports have showed that a payment of Rs. 1000 by citizens as a bribe doubled the chances of timely delivery. However, this was not the scenario in Uruguay and Georgia. Uruguay eliminated the excess cost that the citizens have to bear by maintaining an online platform that would make citizens aware of optimal healthcare services. Further, clear specifications helped citizens understand the possible opportunities for switching healthcare services. Similarly, Georgia also used the digital platform for making the information more accessible and available in different languages so that people could easily learn about services. This electronification reduced the cost that the citizens have to incur on middlemen and hence provided the opportunity of reducing the cost and having effective delivery of services. Thus, this analysis shows that to enable the delivery of services and faster processing of operations at low cost, the Indian government has to look towards increased digitalisation and technological integration in its systems and enhance the connectivity of citizens with the digital world. This would make the process more transparent and eliminate the presence of middlemen in the system.

\section{Conclusion}

With the problem of inequality, poverty, and scarcity, there is a need for every nation to work on effective delivery of available resources to not only attain the social well-being of people but also work towards the sustainable development of the country. However, in the public administration a greater role played by the bureaucracy, lack of transparency, monitoring absence, capacity gaps. and lack of inter-agency coordination not only hampers the mechanism of public service delivery system but also makes an effective delivery of services to the citizens difficult. Coordination strengthens the linkage between the departments and 
with the easy flow of information helps in managing the service delivery process by regulating their activities and monitoring them to reduce the presence of corruption and make the system more transparent for the citizens. However, despite this, the Indian public administration system is still lagging behind in terms of coordination. Although efforts are being made for making services accessible to the citizens, incidents like leakage or non-maintenance of quality still exist. These events not only prevent the citizens from gaining access to the facilities provided by the government but also hamper the living standards of people. With the worsening the human capital of the country, India not only experiences a decrease in its ranking on the human development index but also loses the opportunity to optimally utilise the capacity of people. Considering the devastating impact on sustainable development, this study focused on assessing how coordination is fundamental to effective public service delivery system. For this, a comparison between the government policies of India, Uruguay, and Georgia was drawn. The study on the Public Service Guarantee Act in India, At Your service programme of Uruguay, and Public Administrative Reforms of Georgia shows that in each case the government organizations have worked cordially with other organizations, agencies, or departments to improve the transparency, increase the accessibility of information to the public, enhance institutional capacity, and bring innovation in the functioning. Although India also strived for a successful fulfilment of the objectives of the Act, a lack of coordination and mismanagement, lack of awareness among people,, opaque operational systems and corruption hindered its success. Cases of Uruguay and Georgia show that the use of digital platforms instead of middlemen to deliver public service increases the efficiency of public service delivery. Hence, to avoid the cost that citizens have to bear due to bribing, or lack of awareness, the government of India should focus on digitalisation of the system by encouraging digital connectivity among citizens. This requires efforts like the establishment of a unified portal for information of all services, online grievance and query platform to clear all the doubts of the citizens, and digital training camps in remote areas. These activities would not only make the facilities accessible for the citizens but also help them to avoid the extra cost that they have to bear due to corruption. Hence, coordinated management of the Indian administrative public service delivery system can lead to its effective functioning.

\section{References}

Abierto, G. (2018). Uruguay 's 4 th Open Government National Action Plan 2018-2020.

Afridi, F. (2017). Governance and Public Service Delivery in India. International Growth Centre. https://doi.org/10.1787/9789264083967-3-en

Alexander APD, E. R. (1998). A structural theory of interorganizational coordination: Cases in environmental management . The International Journal of Organizational Analysis, 6(4), 334-354. https://doi.org/10.1108/eb028890

Becker, F. G. (2015). Capacity Building of the Civil Service Bureau of Georgia to Implement the Civil Service Reform. 1-34.

Boella, G., \& Torre, L. van der. (2006). Coordination and Organization. Definitions, 
Examples and Future Research Directions. Electronic Notes in Theoretical Computer Science, 150(3 SPEC. ISS.), 3-20. https://doi.org/10.1016/j.entcs.2006.03.002

Bouckaert, G., Peters, B. G., \& Verhoest, K. (2010). The Coordination of Public Sector Organizations Shifting Patterns of Public Management. In Public Sector Organizations. https://doi.org/10.1057/9780230275256

Chaarlas, L., \& Velmurugan, J. M. (2012). Mahatma Gandhi National Rural Employment Guarantee Act (MGNREGA): Issues and Challenges. International Journal of Physical and Social Sciences, 2(6), 253-261. https://doi.org/10.15373/2249555x/feb2012/8

Drèze, J., \& Khera, R. (2015). Understanding leakages in the public distribution system. Economic and Political Weekly, 50(7), 39-42.

Dreze, J., \& Sen, A. (2013). An Uncertain Glory: India and its Contradictions. https://doi.org/10.1017/beq.2015.5

EU. (2015). Support to Public Administration Reform in Georgia (PAR). (June), 1-20.

Gov.G. E. (2015). Public Administration Reform Roadmap 2020.

Humphreys, P. C. (1998). Improving Public Service Delivery. Public Management Research. Juneja, P. (2015). Definition of Coordination. Retrieved February 12, 2020, from https://www.managementstudyguide.com/coordination.htm

Klijin, E. H., \& Koppenjan, J. (2000). Public Management and Policy Networks: Foundations of a Network Approach to Governance. Public Management, 2(2), 135-158.

Král, J. (2007). Introduction to coordination concept. Human Resources Management \& Ergonomics, 1-6.

Lægreid, P., Verhoest, K., \& Jann, W. (2008). The governance, autonomy and coordination of public sector organizations. Public Organization Review, 8(2), 93-96. https://doi.org/10.1007/s11115-008-0056-5

Malone, T. W. (1988). What is coordination? https://doi.org/10.1016/j.lingua.2003.09.008

Murilidharan. (2016). A New Law Leads to Service Delivery Reforms: The Public Services Guarantee Act.

Nadar, R. N. (2018). Contemporary Issues and Challenges in the Indian Education System. International Journal of Engineering and Management Research, 86-91. https://doi.org/10.31033/ijemr.9.1.05

O’Meally, S., Chowdhury, A., \& Piplani, V. (2017). Public Sector Reform, Citizen Engagement, and Development Results in India. Public Sector Reform, Citizen Engagement, and Development Results in India. https://doi.org/10.1596/28486

OECD. (2008). An implementation guide to ensure accountability and transparency in state ownership. (March), 1-104. 
OECD. (2016). OECD Survey on Planning and Co-ordinating the Implementation of the SDGs: First results and key issues. Retrieved from http://asvis.it/public/asvis/files/OECD_Survey_on_SDGs.pdf

OECD. (2018). Seven key findings from the Youth Governance Survey.

Osborne, P., Hughes, O., \& Kickert, W. (2010). Performance management in the public sector. https://doi.org/10.13140/2.1.2299.9682

Paramashivaiah, P., \& Suresh, B. K. (2016). E- governance: Issues and challenges in India. OIDA International Journal of Sustainable Development.

Peters, B. G. (2018). The challenge of policy coordination. Policy Design and Practice, 1(1), 1-11. https://doi.org/10.1080/25741292.2018.1437946

PWC. (2015). Development of a Long-term Policy Document on provision of citizen-centric administrative services by central state institutions. Retrieved from https://info.undp.org/docs/pdc/Documents/ALB/UNDP_Best Practices Report_PwC final.pdf

Sangokoya, D., Clare, A., Verhulst, S. G., \& Young, A. (2016). Urugay's A Tu Servicio: Empowering Citizens to Make Data Driven Decisions on Health Care. In Govlab.

SAPS. (2014). Tribal Development Plan under "Serv Sewa” Project.

Scrollini, F. (2016). Open your data and will 'they' build it? A case of open data coproduction in health service delivery.

Shah, A. (2005). Public Services Delivery. In The International Bank for Reconstruction and Development / The World Bank. https://doi.org/10.1596/978-0-8213-6140-5

Statista. (2020). Rate of average annual dropout across schools in India in academic year 2016, by level.

Stinchcombe, A. L. (2015). Social structure and organizations. In Economics Meets Sociology in Strategic Management. https://doi.org/10.2307/3094810

Sundar, D. K., Garg, S., \& Garg, I. (Eds.). (2015). Public Health in India: Technology, governance and service delivery.

Thomas, C., \& Rubinstein, H. (2017). Coordination and Governance of Coordination. In Essential Services Package for Women and Girls Subject to Violence Core Elements and Quality Guidelines. Retrieved from http://www.unwomen.org/-/media/headquarters/attachments/sections/library/publications/201 5/essential-services-package-module-5-en.pdf?la=en \&vs=3759

Thornton, G. (2019). Public sector delivery mechanisms : Success story of Madhya Pradesh Contents.

Vanagas, R., \& Stankevič, J. (2015). Impact of coordination for organization process. Intellectual Economics, 8(2), 112. https://doi.org/10.13165/ie-14-8-2-08 


\section{Macrothink}

Journal of Public Administration and Governance ISSN 2161-7104 2020, Vol. 10, No. 3

Vashakidze, G. (2016). One-Stop-Shop Public Service Delivery Model: the Case of Georgia. United Nations Dev. Program. Reg. Hub Civ. Serv. Astana, No.

Vembu, V. (2019). The Indian Administrative Service is in dire need of reform . The Hindu
Business
Line.
Retrieved
from

https://www.thehindubusinessline.com/opinion/the-steel-frames-need-firming-up/article2689 0374.ece

World Bank. (2006). Reforming Public Services in India Drawing Lessons from Success. Health (San Francisco), (35041).

Worldbank. (2018). Improving Public Sector Performance through innovation and inter-agency coordination. In Wold Bank Group. https://doi.org/10.1596/30917

WorldBank. (2015). Project Appraisal Document on a Proposed Credit in the amount of US\$ 35 Million to the Republic of India for a Citizen Access to Responsive Services Project. Retrieved from ttps://www.worldbank.org

\section{Copyright Disclaimer}

Copyright for this article is retained by the author(s), with first publication rights granted to the journal.

This is an open-access article distributed under the terms and conditions of the Creative Commons Attribution license (http://creativecommons.org/licenses/by/4.0/). 